\title{
Raising awareness of health care providers about MERS- CoV infection in public hospitals in Mecca, Saudi Arabia
}

\author{
Mohamed O. Nour ${ }^{1,3}$, Ahmed O. Babalghith ${ }^{2}$, Hatim A. Natto ${ }^{7}$, Sallahaldeen M. Alawneh ${ }^{7}$ and Fowzi O. Elamin ${ }^{1}$
}

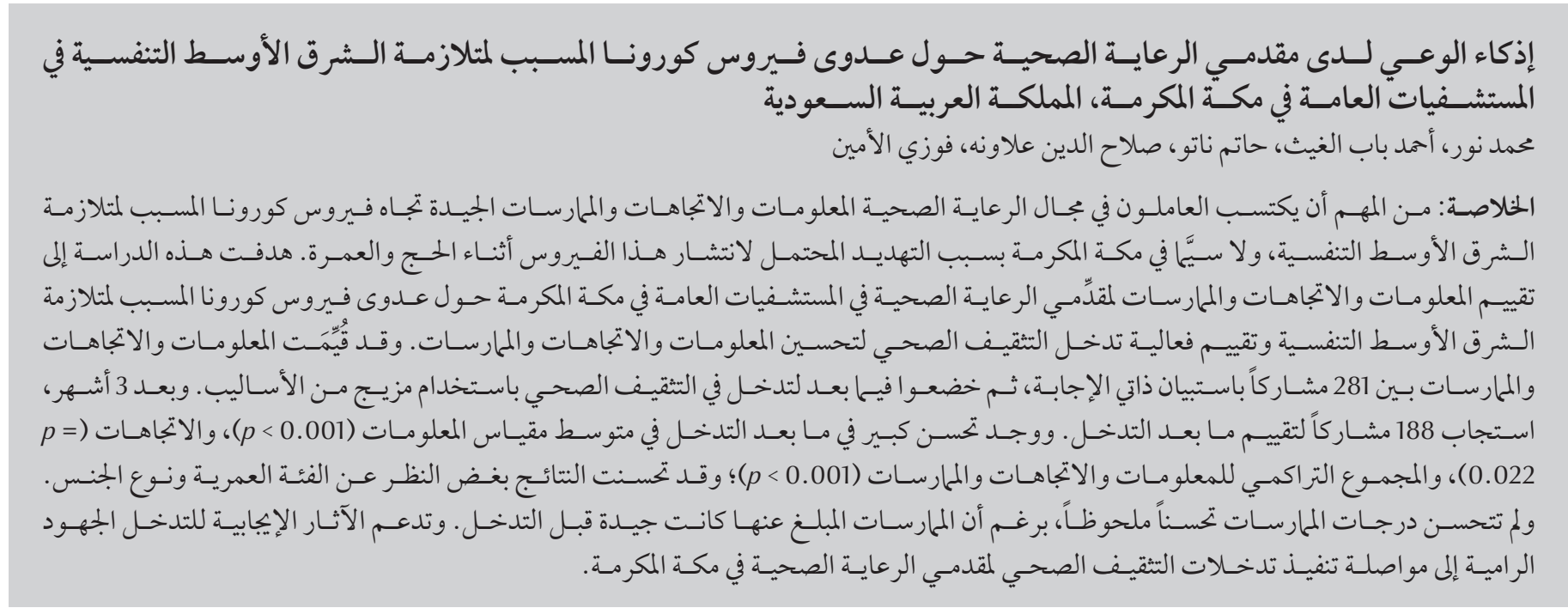

ABSTRACT It is important that health care workers have good knowledge, attitudes and practices (KAP) towards MERS-CoV, especially in Mecca because of the MERS-CoV threat during hajj and umrah. This study aimed to assess KAP of health care providers in public hospitals in Mecca about MERS-CoV infection and evaluate the effectiveness of a health education intervention to improve KAP. KAP was assessed among 281 participants using a self-administered questionnaire who then underwent the health education intervention using a combination of methods. After 3 months, 188 participants responded to the post-intervention evaluation. Significant post-intervention improvement was found in the median scores for knowledge $(P$ $<0.001)$, attitude $(P=0.022)$ and cumulative KAP $(P<0.001)$; scores improved irrespective of age group and gender. Practice scores did not improve significantly, although reported practices were good before the intervention. The positive effects of the intervention support efforts to continuously implement health education interventions for health care providers in Mecca.

Accroître la sensibilisation des prestataires de soins concernant l'infection MERS-CoV dans les hôpitaux de la Mecque (Arabie saoudite)

RÉSUMÉ Pour les agents de santé, il est important d'avoir de bonnes connaissances, attitudes et pratiques concernant l'infection du MERS-CoV, notamment à la Mecque en raison des menaces que représentent cette infection pendant le pèlerinage (Hadj et Omra). L'objectif de la présente étude était d'évaluer les connaissances, attitudes et pratiques des prestataires de soins dans les hôpitaux de la Mecque concernant l'infection du MERS-CoV et d'évaluer l'efficacité de l'intervention d'éducation sanitaire afin d'améliorer ces dernières. Les connaissances, attitudes et pratiques ont été évaluées parmi 281 participants ayant rempli un auto-questionnaire. Ensuite, ceux-ci ont suivi l'intervention d'éducation sanitaire qui recourait à plusieurs méthodes. Trois mois plus tard, 188 participants ont répondu à l'évaluation post-intervention. Une amélioration post-intervention a été constatée concernant les scores médians pour les connaissances $(p<0,001)$, les attitudes $(p=0,022)$ ainsi que le score cumulatif pour les connaissances, attitudes et pratiques $(p<0,001)$; les scores se sont améliorés indépendamment des groupes d'âges et du sexe. L'amélioration au niveau du score médian pour les pratiques n'était pas significative, les pratiques signalées étant bonnes avant l'intervention. Les effets positifs de l'intervention encouragent les efforts visant la mise en ouvre continue de l'intervention d'éducation sanitaire pour les prestataires de soins à la Mecque.

'Department of Health Education and Promotion, Faculty of Public Health and Health Informatics, Umm Al-Qura University, Mecca, Saudi Arabia (Correspondence to: Mohamed O. Nour:drmun78@yahoo.com). ²Department of Medical Genetics, Faculty of Medicine, Umm Al-Qura University, Mecca, Saudi Arabia. ${ }^{3}$ Department of Public Health \& Community Medicine, Faculty of Medicine, Al Azhar University, Damietta Branch, Damietta, Egypt.

Received: 27/07/16; accepted: 30/11/16 


\section{Introduction}

Novel coronavirus, MERS-CoV, is a particular strain different from any other known human coronavirus. It can cause severe acute respiratory illness in humans and transmission is possibly zoonotic (1). As of 2 February, 2016, 1638 laboratory-confirmed cases have been reported to the World Health Organization (WHO) from 26 different countries with 587 related deaths $(2,3)$.

With the gradually increasing number of reported cases, international concern is high about the possibility for this virus to move around the world. Therefore, all countries in the world need to ensure that their health care workers (HCWs) are aware of the virus and the disease it can cause. Furthermore, all countries in Middle East region need to demonstrate how vigilant and prepared they are to prevent international spread of this infection and to support the timely release of research findings. They must put in place enhanced public health surveillance for identifying suspected cases using the WHO-recommended case definition and investigation protocols in order to protect both global health and the wellbeing of the local community $(4,5)$.

In Saudi Arabia, MERS-CoV infection is of great concern at governmental and public levels because the number of infected individuals and deaths is increasing despite extensive work that has been done and is ongoing. This includes a wide range of interventions related to prevention and control procedures, research studies, special measures for people working with animals, risk communications and community engagement, and national, ministerial and international coordination for the investigation and management of cases in the country (5).

From June 2012 to 23 February, 2016, the Ministry of Health of Saudi Arabia reported a total of 1297 confirmed cases with MERS-CoV infection accounting for about $79 \%$ of the global cases; of these, 554 cases died (43\%) accounting for $94 \%$ of total global deaths (6). As regards probable source of infection, since January 2015, 32\% of cases acquired the infection in a health care setting, while $12 \%$ of infected cases were HCWs (6).

Based on the available data and WHO's risk assessment, no sustained human-to-human transmission within communities has been documented and there is no evidence of airborne transmission. However, MERS-CoV is a relatively new disease and there are large gaps in our knowledge including the epidemiological pattern, characteristics of the virus and clinical features (5).

Careful monitoring of the current situation is crucial, particularly in the absence of any prophylactic vaccines or curative treatment and the lack of experience in control measures. There is a concern about possible increased numbers of human infections and deaths during the annual hajj where about 2 million pilgrims come together at the holy places in Saudi Arabia (Mecca and Medina) and throughout the year-round during umrah when about 6 million pilgrims arrive. Until now, little is known about the severity and transmission of this virus in mass gatherings, although no cases have been confirmed during and after hajj. However, special measures need to be taken for pilgrims returning home. On the other hand, during umrah, several cases have been detected and one of the risk factors was a history of visiting a health care setting in Mecca (7).

Health care providers in Mecca hospitals are at risk of infection through occupational exposure to suspected cases during umrah and hajj. They are also expected to participate in health education activities on the infection, particularly if they have relevant information which can be given to patients, and through them, to their families and members of the community. It is important therefore that they have adequate and correct knowledge, attitudes and practices (KAP) towards MERSCoV.

The aim of this study therefore was to evaluate the effect of a health education intervention to improve KAP towards MERS-CoV among health care providers in public hospitals in Mecca.

\section{Methods}

\section{Study design and setting}

This was a quasi-experimental intervention study conducted from September 2014 to October 2015 in public hospitals in Mecca, namely: King Abdul Aziz Hospital, King Faisal Hospital, Al-Nour Specialist Hospital, Ajyad Hospital and Hera General Hospital. It was a continuation of a study with previously published data on the KAP of health care workers in these hospitals (8). In this part participants were given a health education intervention and their KAP re-evaluated after the intervention.

\section{Participants}

The target population, sample size and selection are described previously (8). Briefly, the sample included all health care providers (physicians, specialists, technicians and nurses) in emergency departments in Mecca public hospitals. Inclusion criteria were: working only in emergency departments, direct contact with patients, and willingness to be involved in the study and complete the questionnaire (available on request from the authors)

In the pre-test, we used convenience sampling to find respondents through distribution of a total of 500 questionnaires, taking into consideration drop-outs in the post-test. In the pre-test, the total response rate was $56 \%$ representing 281 out of 500 distributed questionnaires. Among participants who completed the health education intervention, 188 out of 281 (response 
rate of $66.9 \%$ ) completed the postintervention evaluation.

\section{Data collection}

Data were collected using a self-administered questionnaire. Construction, content and scoring of the questionnaire are explained in detail in the previously published paper (8). Briefly, the questionnaire included: 21 questions on knowledge with an overall score of 28 (range 0-28), categorized as good knowledge (score $\geq 21$ ) or poor knowledge (score $<21$ ); 11 questions on attitudes with an overall score of 11 (range $0-11)$, categorized as positive attitudes (score $\geq 8$ ) or negative attitudes (score $<8$ ); and 8 questions on practices with overall score of 8 (range $0-8$ ), categorized as good practices ( score $\geq 6$ ) or poor practices $($ score $<6$ ).

The cumulative KAP score represents the sum of the 3 scores (i.e. 47 points, range $0-47$ ), which was categorized as good cumulative KAP (score $\geq 35$ ) or poor cumulative KAP (score $<35$ ). All scores were categorized into good/positive or poor/negative based on a $75 \%$ cut-off point out of the total expected score for each.

Each questionnaire, in both pre-and post-tests, was evaluated for missing data at the time of submission and corrected in the presence of the respondent to make sure each question was answered.

Analysis of the pre-intervention data is described previously (8). We identified certain areas where participants had less knowledge, negative attitudes and/ or poor practices to be covered during the health education intervention.

\section{Health education intervention}

In coordination with training and education centres in each hospital, all available participants were given the first health education session about the epidemiology of MERS-CoV infection immediately after they completed the questionnaire for the first time. The second session was held after 1 week and was on prevention and control measures. Both sessions (60 minutes each) were based on the most recent available data with a summary takehome message about protecting oneself from infection. The sessions included presentations, brainstorming, interactive discussion and a short video. Based on pre-test observations, to provide knowledge and reinforce attitudes by feedback, we developed 5 large banners and distributed posters, brochures and pamphlets in both Arabic and English on different epidemiological aspects and prevention and control measures prepared from the WHO, Centers for Disease Control and Prevention, Atlanta and Saudi Ministry of Health media websites $(1-3,5,6)$. As commitment to proper infection prevention and control measures would result in a decrease in the risk of occupational exposure to infection, we emphasized the infection control measures through demonstrations of proper handwashing techniques, cough etiquette, use of personnel protective equipment and safe disposal of contaminated objects with the help of infection control unit in each hospital. In addition, with the help of the training and education centre in each hospital and with the support and supervision of local health authorities, short health education messages were sent regularly as reminders to the mobile telephones of the participants using WhatsApp for 2 months after the intervention. In addition, the banners, posters, brochures and educational videos were continuously presented on television screens distributed in different parts of each hospital. As requested by the health authorities, all these services were available to the whole hospital team and not only to the target group.

\section{Post-test evaluation}

We measured the change in the KAP of the participants about 3 months after the intervention using the same selfadministered questionnaire used in the pre-test.

\section{Ethical considerations}

The study was approved by the bioethics committee at Umm Al-Qura University (project \# 43409062), the research ethical committee at Al-Noor Specialist Hospital (No. 512267\302\47) and the Directorate of Health Affairs. Verbal consent was obtained from respondents before participation in the study; the objectives and benefits of the study were explained to the participants and they were assured of the confidentiality of the data.

\section{Statistical analysis}

SPSS, version 19.0 was used for data analysis. Fisher exact tests were used to compare qualitative variables. The data were not normally distributed and accordingly median and non-parametric tests were used: Mann-Whitney test for dichotomous variables and KruskalWallis test when there was more than 2 subgroups of respondents. All $P$-values were two-tailed, assuming a significance level of $P<0.05$.

\section{Results}

\section{Pre- and post-intervention KAP scores}

A total of 188 health care providers were evaluated for changes in their KAP scores before and after the health education intervention. Our results showed a significant post-intervention improvement in their good knowledge score $(P<0.001)$, positive attitude score $(P=$ $0.008)$ and good cumulative KAP score $(P=0.001)$. There was a non-significant increase in self-reported good practice score by about $4 \%(P=0.168)$ (Figure 1).

\section{Knowledge}

Table 1 shows the number of health care providers with good knowledge about MERS-CoV infection before and after the intervention. The number with good knowledge improved after the intervention with regard to knowledge 


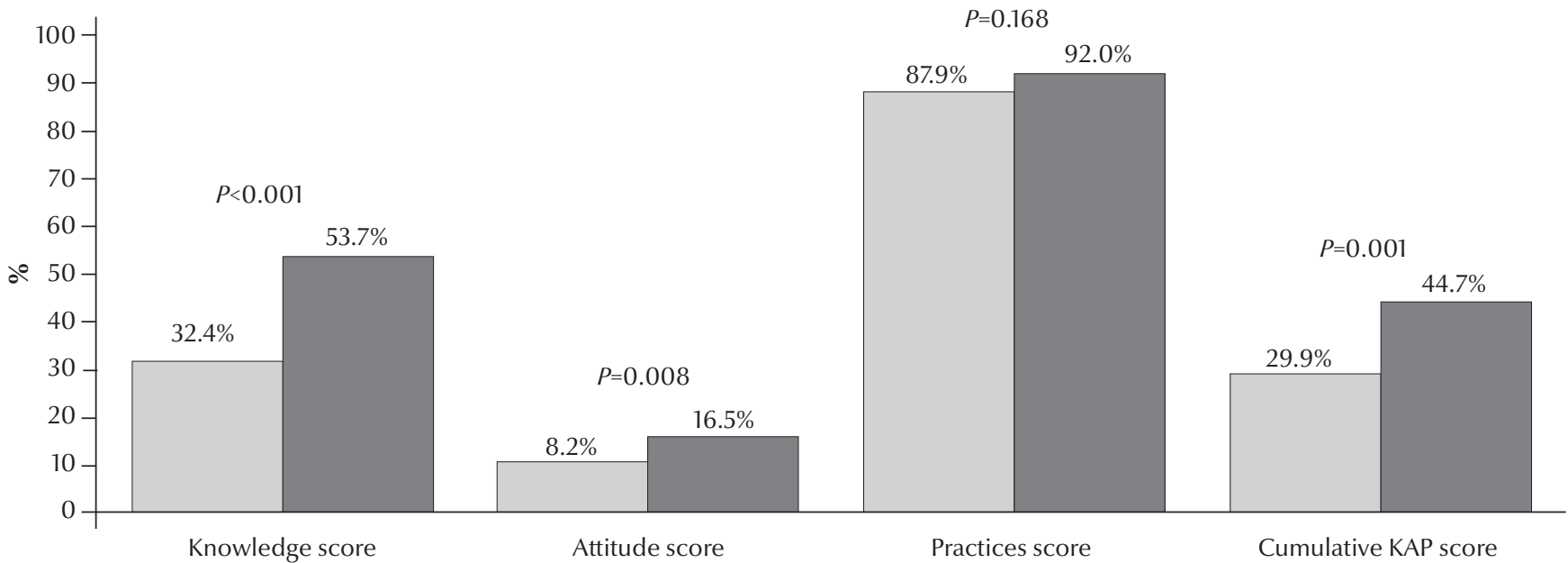

Pre-test

Post-test

Figure 1 Overall good/positive knowledge, attitudes and practices (KAP) scores of health care providers about MERS-CoV before and after the health education intervention, Mecca, Saudi Arabia

\begin{tabular}{|c|c|c|c|c|}
\hline \multirow[t]{2}{*}{ Knowledge questions } & \multicolumn{2}{|c|}{ Correct responses } & \multirow{2}{*}{$\begin{array}{l}\text { Fisher exact } \\
\text { value }\end{array}$} & \multirow[t]{2}{*}{$P$-value ${ }^{1}$} \\
\hline & $\begin{array}{c}\text { Pre-test } \\
(n=281) \\
\text { No. }(\%)\end{array}$ & $\begin{array}{l}\text { Post-test } \\
(n=188) \\
\text { No. }(\%)\end{array}$ & & \\
\hline Causative agent & $264(94.0)$ & $178(94.7)$ & 0.11 & 0.841 \\
\hline Reservoir of infection & $142(50.5)$ & $132(70.2)$ & 17.9 & $<0.001$ \\
\hline Source of infection & $259(92.2)$ & $179(95.2)$ & 1.05 & 0.335 \\
\hline Transmission from an infected person to another & $264(94.0)$ & $180(95.7)$ & 0.72 & 0.530 \\
\hline Methods of transmission & $194(69.0)$ & $154(81.9)$ & 9.78 & 0.008 \\
\hline Transmission through renal dialysis & $116(41.3)$ & $111(59.0)$ & 14.23 & $<0.001$ \\
\hline Characteristics of infected cases in Saudi Arabia & $180(64.0)$ & $148(78.7)$ & 12.37 & 0.002 \\
\hline Incubation period in humans & $166(59.1)$ & 139 (73.9) & 10.94 & 0.001 \\
\hline Disease manifestations in humans & $163(58.0)$ & $149(79.3)$ & 29.10 & $<0.001$ \\
\hline Risk level among health care providers & $259(92.2)$ & $181(96.3)$ & 3.27 & 0.080 \\
\hline Risk of death if delay in seeking treatment & $265(94.3)$ & $179(95.2)$ & 0.18 & 0.834 \\
\hline Isolation of suspected cases in the emergency department & $238(84.7)$ & $174(92.6)$ & 6.51 & 0.014 \\
\hline $\begin{array}{l}\text { Recommendations when admitting suspected/confirmed } \\
\text { cases at hospital }\end{array}$ & $150(53.4)$ & $128(68.1)$ & 10.09 & 0.006 \\
\hline Recommendations for contact of confirmed cases at home & $202(71.9)$ & $158(84.0)$ & 10.08 & 0.006 \\
\hline Diagnosis of disease in humans & $213(75.8)$ & $159(84.6)$ & 8.01 & 0.018 \\
\hline Availability of vaccine & $208(74.0)$ & $166(88.3)$ & 14.21 & $<0.001$ \\
\hline Protection by seasonal influenza vaccine & $167(59.4)$ & $137(72.9)$ & 8.93 & 0.003 \\
\hline WHO travel ban to Saudi Arabia & $158(56.2)$ & $137(72.9)$ & 13.37 & $<0.001$ \\
\hline Methods of providing health care to patients & $138(49.1)$ & $129(68.6)$ & 17.73 & $<0.001$ \\
\hline Possible cure from infection & $231(82.2)$ & $165(87.8)$ & 2.65 & 0.119 \\
\hline Time to return to daily activities if cured & $86(30.6)$ & $122(64.9)$ & 53.66 & $<0.001$ \\
\hline
\end{tabular}

${ }^{'}$ Boldface indicates statistically significant difference. 
about: reservoir of infection, transmission through renal dialysis, disease manifestations in humans, availability of a vaccine, travel ban to Saudi Arabia, methods of providing health care to patients and time to return to daily activities in case of cure $(P<0.001)$, incubation period in humans $(P=$ $0.001)$, characteristics of Saudi Arabian infected cases $(P=0.002)$, protection by seasonal influenza vaccine $(P=0.003)$, recommendations when admitting suspected/confirmed case to hospital and recommendations for contact with confirmed case at home $(P=0.006)$, methods of transmission of infection to humans $(P=0.008)$, isolation of suspected cases in the emergency department $(P=0.014)$ and diagnosis of disease in humans $(P=0.018)$ (Table 1).

\section{Attitudes}

Table 2 shows the number of health care providers with positive attitudes about MERS-CoV infection before and after the intervention. The number with positive attitudes increased after the intervention with regard to: negative impact of coronavirus infection on the Saudi Arabian economy, fear of going to public places in case they became infected $(P<0.001)$, preventability of coronavirus infection, fear of one of their family members acquiring the infection $(P=0.002)$, treatment of coronavirus infection at home $(P=0.005)$, use of a face mask during working hours, role of health education in disease prevention $(P=0.008)$ and closure of schools and work places in case of an epidemic $(P=$ 0.031) (Table 2)

\section{Practices}

Table 3 shows the number of health care providers with a good practices in relation infection control before and after the intervention. The number with good infection control practices did not increase significantly after the intervention $(P=0.168)$ (Table 3).

\section{KAP scores among subgroups}

Comparison of median KAP scores before and after the intervention among various subgroups of respondents (categorized by age, sex, occupation and years of experience) is shown in Table 4.

The overall median knowledge, attitudes and cumulative scores improved after the intervention $(P<0.001, P=$ 0.022 and $P<0.001$ respectively). However, no significant improvement was seen in the median practices score $(P$ $=0.591$ ).

The median knowledge and cumulative KAP scores improved significantly after the intervention among the different subgroups of participants except for physicians and those with experience $>$ 10 years. The median attitudes scores became significantly more positive after the intervention among both age

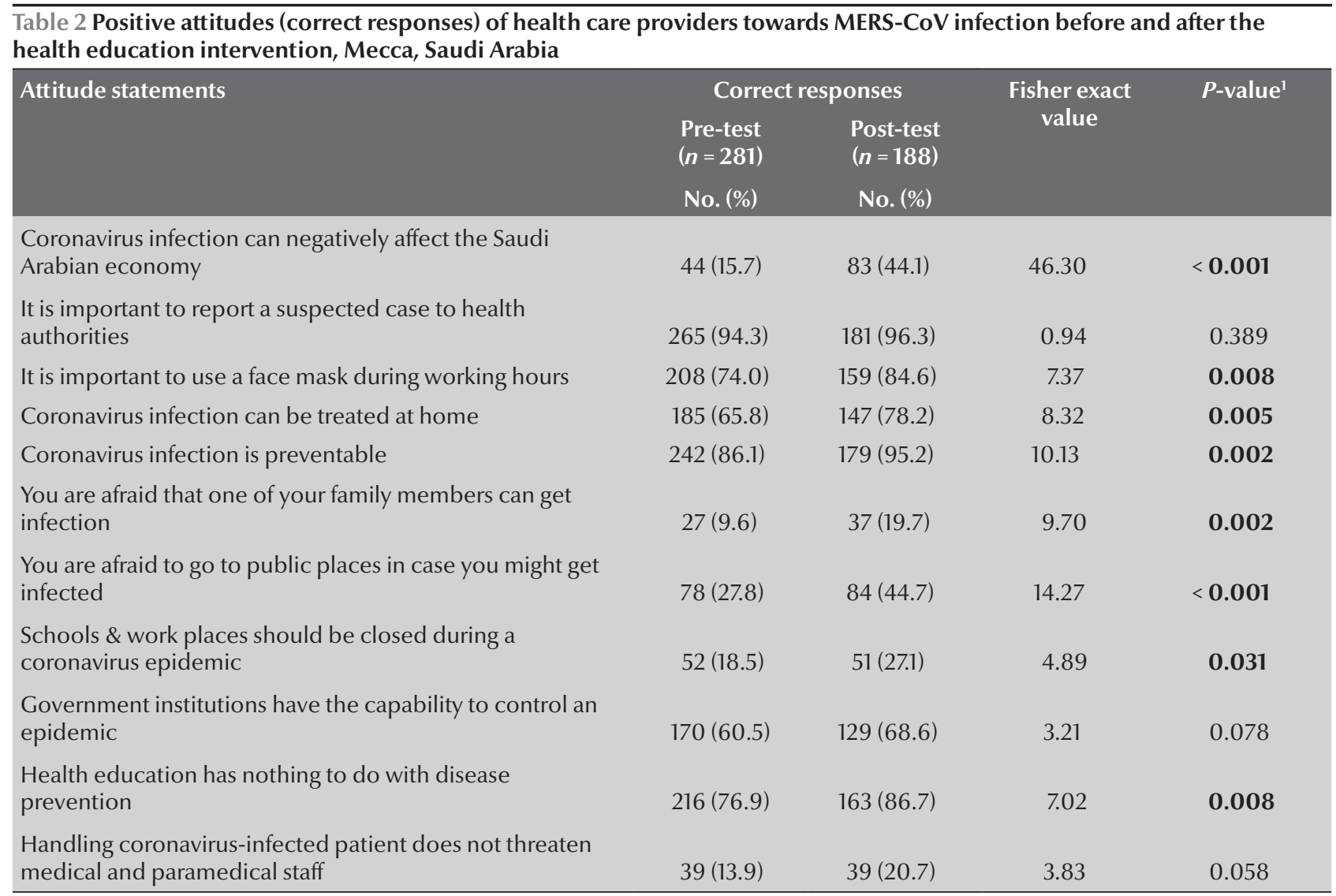

${ }^{'}$ Boldface indicates statistically significant difference. 


\begin{tabular}{|c|c|c|c|c|}
\hline \multirow[t]{2}{*}{ Practices statements } & \multicolumn{2}{|c|}{ Correct responses } & \multirow{2}{*}{$\begin{array}{c}\text { Fisher exact } \\
\text { value }\end{array}$} & \multirow[t]{2}{*}{$P$-value } \\
\hline & $\begin{array}{l}\text { Pre-test } \\
(n=281) \\
\text { No. }(\%)\end{array}$ & $\begin{array}{l}\text { Post-test } \\
(n=188) \\
\text { No. }(\%)\end{array}$ & & \\
\hline \multirow{3}{*}{$\begin{array}{l}\text { I use soap and water to wash my hands continuously } \\
\text { I cover my nose and mouth with a tissue while sneezing or } \\
\text { coughing } \\
\text { I throw the used tissue in the trash }\end{array}$} & $257(91.5)$ & $176(93.6)$ & 0.74 & 0.480 \\
\hline & $262(93.2)$ & $179(95.2)$ & 0.78 & 0.431 \\
\hline & $268(95.4)$ & $179(95.2)$ & 0.01 & 1.000 \\
\hline Avoid touching my eyes, nose or mouth as much as I can & $264(94.0)$ & $180(95.7)$ & 0.72 & 0.530 \\
\hline I use face mask in crowds & $234(83.3)$ & $166(88.3)$ & 2.27 & 0.145 \\
\hline I carefully handle suspected patient's belongings & $259(92.2)$ & $177(94.1)$ & 0.67 & 0.465 \\
\hline I have healthy eating and lifestyle habits & $253(90.0)$ & $173(92.0)$ & 0.53 & 0.517 \\
\hline I have educated clients about the disease & $219(77.9)$ & $154(81.9)$ & 1.10 & 0.350 \\
\hline
\end{tabular}

groups and genders and among nurses and those with $<5$ years' experience. There was no significant improvement in the median practices scores after the intervention among all subgroups.

\section{Discussion}

To the best of our knowledge, this is the first intervention study in the western area of Saudi Arabia to raise awareness of health care providers about MERS$\mathrm{CoV}$ through a health education intervention.

\section{Knowledge}

The health education intervention helped to raise the knowledge of participants about MERS-CoV in many areas. However, although the present findings were positive overall, some areas merit concern. For example, a large proportion of the health care providers did not have correct knowledge about the incubation period. Some participants before the intervention might not have considered the importance of the incubation period in infectious disease surveillance and control, in diagnosis if laboratory facilities are unavailable and that it is clinically relevant in administration of antiviral medications, which are most effective when given before or immediately after the onset of symptoms (9). Furthermore, our findings related to the recommended action when dealing with a suspected/confirmed case in hospital and for close contacts at home also give rise to concern. Dealing with a suspected/confirmed case is inevitable whether by health care providers at hospital or close contacts at home, and good knowledge and commitment to these recommendations is vital to avoid transmission of infection $(10,11)$.

\section{Attitudes}

The health education intervention helped improve some attitudes about MERS-CoV. Studies have shown varying attitudes towards MERS-CoV and other related infections. About three quarters (74.5\%) of Japanese HCWs accepted the risk of a potential influenza pandemic, $64.5 \%$ were afraid and $26.4 \%$ would consider changing their jobs (12). The majority of HCWs in Thailand (90\%) accepted the occupational risk of caring for H5N1-infected patients (13). Closure of schools in the case of an H1N1 influenza epidemic was accepted by about $78 \%$ of the Saudi Arabian public (14).

The use of personal protective equipment by HCWs at $\mathrm{Al}$ Qassim region was reported to be the most positive attitude when dealing with MERS-CoV (15). In the same context, Thu et al. reported a similar positive attitude of HCWs when dealing with health care-associated infections (16).
An Iranian study reported a positive attitude among Iranian HCWs regarding the importance of active participation by health education in prevention programmes (17). However, a negative attitude among HCWs at Al Qassim region was observed regarding the usefulness of active participation in infection control programmes in reducing the prevalence of MERS-CoV (15).

There was some inconsistency with regard to knowledge and attitude responses. Although after the intervention $68 \%$ of participants reported good knowledge about the recommendations for dealing with a suspected/confirmed MERS-CoV case in hospital, about $80 \%$ believed that handling a coronavirusinfected patient was a threat to their health. This contradicts Green et al.'s suggestion that increased identifiable knowledge results in increased identifiable attitude (18).

\section{Practices}

Generally, the self-reported infection control practices of the participants in relation to MERS-CoV infection were good both before and after the intervention, although this was not the ideal way of measuring practices.

These results support the findings of a study in Saudi Arabia which reported a high level of compliance with infection control practices among HCWs, with no difference between doctors 


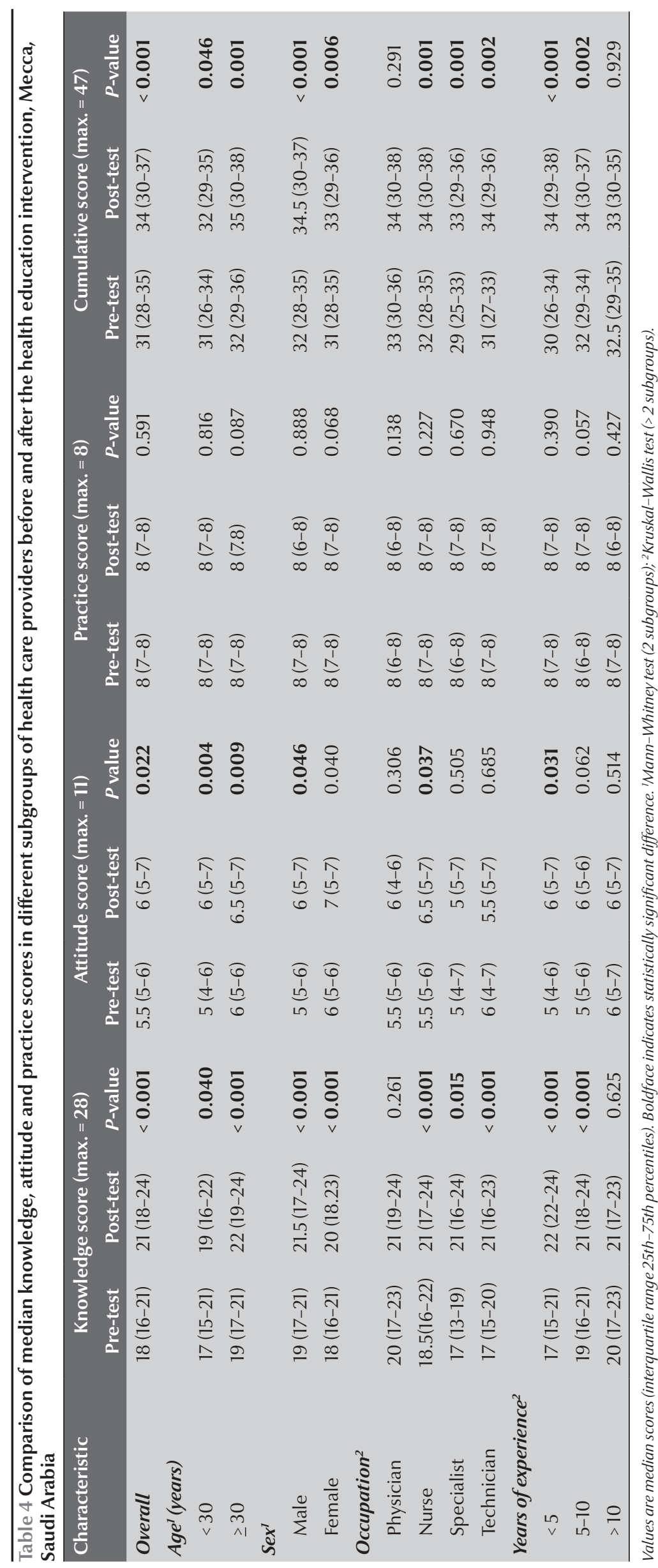

and nurses (19), and a study in Taiwan which reported good compliance among infection control nurses with hand washing guidelines (20). However, a Vietnamese study reported only a few correct responses to items about hand hygiene and the use of surgical masks (16), and a study in Saudi Arabia found that about $60 \%$ of the Saudi Arabian public took few self-reported precautionary measures regarding swine flu (14).

Our results should be interpreted with caution, particularly with regard infection control practices which were self-reported and not actually observed. Some participants may not express their real thoughts, beliefs and understandings and this may have an effect on their responses (21).

\section{Participant characteristics and KAP scores}

Knowledge and cumulative KAP scores significantly improved after the intervention in both age groups and genders, in all occupations except physicians, and in all years of experience except > 10 years. Attitude scores also improved significantly overall and in both age groups and genders, in nurses and in those with $<5$ years' experience. The association between KAP and age, gender, specialty or experience is supported by some reports $(15,22-24)$ but not others (13). Some studies explained the better knowledge among physicians compared with other health care providers by their greater opportunities for professional development and clinical training (15). Gender and experience were found to be important predictors of knowledge and attitude of HCWs in some studies $(15,22,25-27)$, while other research does not support this (28). Some research has suggested that the traditional norms and customs in Saudi Arabia might explain the effect of gender on KAP of HCWs. Male health workers have more interaction and socialization than females, more opportunities to meet other health care 
professionals and specialists, travelling for symposiums, conferences and other health-related activities, and are more exposed to health care systems compared with their female counterparts (29).

Because of the multifaceted nature of the intervention, it is difficult to determine to what extent the individual strands of the intervention (health education sessions, provision of knowledge, feedback of results, hands-on demonstration and reminder services) may have contributed to the overall improvement that occurred. This supports the theory that, in order to achieve behavioural change, attention must be paid to all the factors that predispose, reinforce and enable behaviour and not just to a single factor (18).

Some studies have reviewed the effects of health education on KAP of $\mathrm{HCW}$ at various time intervals. In India, assessing post-education KAP scores showed that the best scores were achieved in the first post-education assessment conducted 6 months after the intervention. However, improvement declined in the second assessment at 12 months and dropped still further in the third assessment after 24 months (30). On the other hand, other studies found that passing time did not negatively affect KAP and it can even improve KAP if education is continuous $(31,32)$. Thus, continuous education, efficient in-service training, monitoring and evaluation of HCW practices play an important role in retention of knowledge and application of infection control practices (33).

It is important to interpret our results in the context of potential study limitations. First, our study was conducted only among health care providers in public hospitals and does not represent the private sector or other HCWs such as patient supporters and cleaners. Second, information was obtained from health care providers who were on duty during the study. Those not on duty were excluded and information on their characteristics and their possible responses is unknown. In addition, because of various constraints, we could not gather all the health team simultaneously for the educational intervention. So the number of post-intervention participants was markedly lower. Third, there may have been reporting bias; the participants who received the health education intervention may be more likely to report practices consistent with proper infection control procedures (social desirability bias). Fourth, participants could have acquired different levels of knowledge through other means, e.g. mass media, books, articles or conferences, which would have influenced their responses and the study results. Fifth, the 3-month post intervention period was relatively short and the longterm effect of the intervention should be investigated. Sixth, the effect of the intervention may diminish over time. So, periodic repetition of educational programmes may help maintain health care providers' awareness of MERSCoV. Finally, our study did not include a control group who did not receive the education intervention. This would have increased the power of the study and reduced bias.

In spite of the limitations, our study highlighted some gaps in the KAP of health care providers in Mecca and showed that the health education intervention, using different methods, succeeded in improving knowledge, attitudes and cumulative scores. The positive results of this intervention and the extent of the current MERS-CoV threat during the hajj and umrah seasons support efforts to continuously implement health education intervention programmes for health care providers, especially in Mecca. Rigorous evaluation of these programmes would be of great value.

\section{Acknowledgements}

The authors would like to thank the Institute of Scientific Research and Revival of Islamic Heritage at Umm Al-Qura University for the financial support.

Funding: Institute of Scientific Research and Revival of Islamic Heritage at Umm Al-Qura University, Mecca (project\# 43409062).

Competing interests: None declared.

\section{References}

1. Centers for Disease Control and Prevention. Coronavirus home: about coronavirus. [webpage] (http://www.cdc.gov/ coronavirus/about/index.html, accessed 3 May 2017).

2. World Health Organization. Emergency Preparedness and Response. Middle East respiratory syndrome-coronavirus (MERS-CoV) - Saudi Arabia. Disease outbreak news 2 February 2016 [webpage] (http://www.who.int/csr/don/2-february2016-mers-saudi-arabia/en/, accessed 3 May 2017).

3. World Health Organization. Middle East Respiratory Syndrome-coronavirus (MERS-CoV) [webpage] (http://www. who.int/emergencies/mers-cov/en/, accessed 3 May 2017).

4. Malik M, Mahjour J, Opoka M, Mafi A. Emergence of novel human coronavirus: public health implications in the
Eastern Mediterranean Region. East Mediterr Health J. 2012;18(11):1084-5.

5. World Health Organization. Middle East Respiratory Syndrome-coronavirus (MERS-CoV). Summary of current situation, literature update and risk assessment. (WHO/MERS/ RA/15.1) (http://www.who.int/iris/bitstream/10665/179184/ http://apps.who.int//iris/bitstream/10665/179184/2/ WHO_MERS_RA_15.1_eng.pdf?ua=1 accessed 3 May 2017).

6. Command and Control Center, Ministry of Health, Saudi Arabia. Coronavirus statistics [website] http://www.moh.gov. sa/en/CCC/PressReleases/Pages/Statistics-2016-02-23-001. aspx, accessed 3 May 2017). 
7. Soliman T, Cook AR, Coker RJ. Pilgrims and MERS-CoV: what's the risk? Emerg Themes Epidemiol. 2015;12:3.

8. Nour MO, Babilghith AO, Natto HA, Al-Amin FO, Alawneh SM. Knowledge, attitude and practices of healthcare providers towards MERS-CoV infection at Makkah hospitals, KSA. Int Res J Med Med Sci. 2015;3(4):103-12.

9. Lessler J, Reich NG, Brookmeyer R, Perl TM, Nelson KE, Cummings DA. Incubation periods of acute respiratory viral infections: a systematic review. Lancet InfectDis. 2009;9(5):291-300.

10. Assiri A, McGeer A, Perl TM, Price CS, Al Rabeeah AA, Cummings DA, et al. Hospital outbreak of Middle East respiratory syndrome coronavirus. N Engl J Med. 2013;369(5):407-16.

11. Memish ZA, Zumla Al, Assiri A. Middle East respiratory syndrome coronavirus infections in health care workers. N Engl J Med. 2013;369:884-6.

12. Imai $\mathrm{T}$, Takahashi $\mathrm{K}$, Todoroki $\mathrm{M}$, Kunishima $\mathrm{H}$, Hoshuyama $\mathrm{T}$, Ide $\mathrm{R}$, et al. Perception in relation to a potential influenza pandemic among healthcare workers in Japan: implications for preparedness. J Occup Health. 2008;50(1):13-23.

13. Apisarnthanarak A, Phattanakeitchai P, Warren DK, Fraser VJ Impact of knowledge and positive attitudes about avian influenza (H5N1 virus infection) on infection control and influenza vaccination practices of Thai healthcare workers. Infect Control Hosp Epidemiol. 2008;29(5):472-4.

14. Balkhy HH, Abolfotouh MA, Al-Hathlool RH, Al-Jumah MA Awareness, attitudes, and practices related to the swine influenza pandemic among the Saudi public. BMC Infect Dis. 2010;10:42.

15. Khan MU, Shah S, Ahmad A, Fatokun O. Knowledge and attitude of healthcare workers about middle east respiratory syndrome in multispecialty hospitals of Qassim, Saudi Arabia. BMC Public Health. 2014;14(1):1281.

16. Thu TA, Anh NQ, Chau NQ, Hung NV. Knowledge, attitude and practices regarding standard and isolation precautions among Vietnamese health care workers: a multicenter cross-sectional survey. Intern Med. 2012;2(4):115.

17. Rahnavardi M, Rajaeinejad M, Pourmalek F, Mardani M, Holakouie-Naieni K, Dowlatshahi S. Knowledge and attitude toward Crimean-Congo haemorrhagic fever in occupationally at-risk Iranian healthcare workers. J Hosp Infect. 2008;69(1):77-85.

18. Green L, Kreuter M, Deeds S, Partridge K. Health education planning: a diagnostic approach. Palo Alto (CA): Mayfield Publishing Co.; 1980.

19. Al Saleh EM. Ibrahim A, Mwanri L. Healthcare workers' knowledge, attitudes and practices in King Fahad Hofuf Hospital, Saudi Arabia. J Pharm Biomed Sci. 2014;4(3):410-21.

20. Pan S-C, Tien K-L, Hung I-C, Lin Y-J, Sheng W-H, Wang M-J, et al. Compliance of health care workers with hand hygiene practices: independent advantages of overt and covert observers. PLoS ONE 2013;8(1): e53746.
21. Zemore SE. The effect of social desirability on reported motivation, substance use severity, and treatment attendance. J Subst Abuse Treat. 2012; 42(4):400-2.

22. Kheshti R, Namazi S, Mehrabi M, Firouzabadi D. Health care workers' knowledge, attitude, and practice about chronic pain management, Shiraz, Iran. Anesth Pain Med. 2016;6(4):e37270.

23. Joukar F, Mansour-Ghanaei F, Soati F, Meskinkhoda P. Knowledge levels and attitudes of health care professionals toward patients with hepatitis C infection. World J Gastroenterol. 2012;8:2238-44.

24. Gizaw GD, Alemu ZA, Kibret KT. Assessment of knowledge and practice of health workers towards tuberculosis infection control and associated factors in public health facilities of Addis Ababa, Ethiopia: a cross-sectional study. Arch Public Health. 2015;73(1):15.

25. Amin T, Al Wehedy A. Healthcare providers' knowledge of standard precautions at the primary healthcare level in Saudi Arabia. Healthcare Infect. 2009;14(2):65-72.

26. Alazmy SF, Alotaibi DM, Atwan AA, Kamel MI, El-Shazly MK. Gender difference of knowledge and attitude of primary health care staff towards domestic violence. Alex J Med. 2011;47(4):337-41.

27. Almutairi KM, Al Helih EM, Moussa M, Boshaiqah AE, Saleh Alajilan A, Vinluan JM, et al. Awareness, attitudes, and practices related to coronavirus pandemic among public in Saudi Arabia. Fam Community Health. 2015;38(4):332-40.

28. Akpodiete A, Isara AR. Concerns about the knowledge of multi drug resistant tuberculosis among health care workers and patients in southern Nigeria. Am J Respir Crit Care Med. 2014;189:A3215.

29. Al Alhareth $\mathrm{Y}, \mathrm{Al}$ Alhareth $\mathrm{Y}, \mathrm{Al}$ Dighrir I. Review of women and society in Saudi Arabia. Am J Educ Res. 2015;3(2):121-5.

30. Suchitra JB, Lakshmi Devi N. Impact of education on knowledge, attitudes and practices among various categories of health care workers on nosocomial infections. Indian J Med Microbiol. 2007;25(3):181-7.

31. Yilmaz G, Caylan R, Aydin K, Topbas M, Koksal I. Effect of education on the rate of and the understanding of risk factors for intravascular catheter-related infections. Infect Control Hosp Epidemiol. 2007;28(6):689-94.

32. Yousefi H, Nahidian M, Sabouhi F. Reviewing the effects of an educational program about sepsis care on knowledge, attitude, and practice of nurses in intensive care units. Iranian J Nurs Midwifery Res. 2012;17(2) Suppl1:S91-5.

33. Saleh DA, Elghorory LM, Shafik MR, Elsherbini EE. Improvement of knowledge, attitudes and practices of health care workers towards the transmission of blood-borne pathogens: an intervention study. J Egypt Public Health Assoc. 2009;84(56):423-41. 